\title{
Prática pedagógica de enfermeiros de Saúde da Família no desenvolvimento da Educação em Saúde*
}

Edmar Rocha Almeida ${ }^{(a)}$

Cinara Botelho Moutinho(b)

Maisa Tavares de Souza Leite ${ }^{(c)}$

Almeida ER, Moutinho CB, Leite MTS.Family health nurses' teaching practice in the health education development. Interface (Botucatu). 2016; 20(57):389-401.

This study aimed to analyze, from the nurses' perception, the health education practice on the Family Health Strategy in Montes Claros, MG, Brazil. This is a qualitative, descriptive and dialectical research whose residents were eight nurses in the family health. The data were collected through unstructured interviews, recorded and transcribed for further discourse analysis. The results revealed two dichotomous empirical categories: the hegemonic health education, and the dialogic practice. Contradictory discourses were found, where at the same time the subjects describe a participatory and problem-based education while at the same time they report practices based in the imposition of ideas and forcing conditions to the population. The study showed how reality has plural faces and how it evolves in flows and ebbs.

Keywords: Health education. Family health. Primary health care. Community health nursing. Qualitative research.
Este estudo objetivou analisar, a partir da percepção de enfermeiros, a prática da educação em saúde no contexto da Estratégia Saúde da Família de Montes Claros, MG, Brasil. Trata-se de uma investigação qualitativa, descritiva e dialética cujos sujeitos foram oito enfermeiros residentes em saúde da família. Os dados foram coletados por entrevistas não estruturadas gravadas e transcritas para posterior análise do discurso. Os resultados revelaram duas categorias empíricas dicotômicas: a educação em saúde hegemônica e a prática dialógica. As contradições do discurso foram evidenciadas, pois, ao mesmo tempo em que os sujeitos descrevem uma educação participativa e problematizadora também relatam práticas baseadas na imposição de ideias e condicionamento da população. Deste modo, ficou demonstrada a pluralidade da realidade com avanços e retrocessos, traduzindo seu devir.

Palavras-chave: Educação em saúde. Saúde da família. Atenção primária à saúde. Enfermagem em saúde comunitária. Pesquisa qualitativa.

\footnotetext{
"Baseado em "Educação em saúde na estratégia saúde da família: a visão do enfermeiro e do usuário", pesquisa aprovada pelo Comitê de Ética em Pesquisa da Universidade Estadual de Montes Claros e financiada pela Fundação de Amparo à Pesquisa do Estado de Minas Gerais, como parte do Programa Institucional de Iniciação Científica da Unimontes.

(a) Departamento de Saúde e Saneamento, Prefeitura de Taiobeiras. Travessa Laurinda Angélica, $n^{\circ}$ 42, Centro. Taiobeiras, MG, Brasil. 39550-000. edsky48@gmail.com

(b) Programa de Residência de Enfermagem em Saúde da Mulher, Hospital Universitário Clemente de Faria,

Universidade Estadual de Montes Claros. Montes Claros, MG, Brasil.cinarabotelho@ yahoo.com.br

(c) Programa de PósGraduação em Ciências da Saúde, Centro de Ciências Biológicas e da Saúde, Universidade Estadual de Montes Claros. Montes Claros, MG, Brasil. mtsiv@terra.com.br
} 


\section{Introdução}

A evolução no conceito da saúde nos leva a entendê-la como produto de múltiplas influências, moldada em um meio social, cultural e econômico. Essa compreensão considera como determinantes diversos fatores entrelaçados e de comportamento dinâmico, como: o ambiente social, a prática dos profissionais da área e as características culturais da população. O debate sobre esses aspectos tem influenciado a reorganização dos serviços de saúde e a revisão de suas estratégias de intervenção em todo o mundo'1.

Nessa conjuntura, no Brasil, surge a Estratégia Saúde da Família (ESF) como política pública que pressupõe práticas e princípios da Atenção Primária à Saúde (APS) e materializa o fazer e o pensar a saúde em um modelo voltado para a lógica de intervenção territorial. A ESF trabalha com o desafio de conduzir a inversão do modelo assistencial por meio do trabalho em equipe multiprofissional capaz de produzir cuidado longitudinal e integral para uma população adscrita. Além disso, no seu cotidiano, utiliza-se de tecnologias complexas, porém, menos densas, pautadas nas relações sociais, como é o caso da educação em saúde ${ }^{2}$.

Entende-se por educação a utilização de processos e técnicas pedagógicas para a socialização de conhecimentos e formação de sujeitos, tendo como base as diversas relações humanas s $^{3,4}$. Assim, pode-se conceituar a educação em saúde como a utilização desses processos e técnicas para o compartilhamento de saberes sobre saúde que podem influenciar o cotidiano das pessoas, possibilitando a melhoria de sua qualidade de vida ${ }^{5}$. Também, possui um enfoque político, quando utilizada como canal de exercício da cidadania e controle social nos serviços de saúde ${ }^{6}$.

$\mathrm{Na}$ realidade social, ambiente em que a educação em saúde acontece, existem variadas formas de desenvolvê-la por meio de modelos pedagógicos que sempre estão conectados a uma forma de perceber o mundo, a saúde e a uma visão educativa específica ${ }^{5,7}$. Da mesma forma, toda prática pedagógica reflete as ideologias impregnadas em um dado contexto e, ao mesmo tempo, influencia as ações individuais e coletivas, pois não existe educação neutra ou apolítica 8.9 .

A partir da revisão de vários autores, podem-se dividir as práticas pedagógicas da educação em saúde em dois grupos cujos métodos e objetivos são contraditórios. O primeiro é denominado modelo de educação em saúde hegemônico, e, o segundo, dialógico ${ }^{5-7}$.

No modelo hegemônico, observa-se que o principal objetivo é fazer com que as pessoas mudem seus comportamentos a fim de obterem melhor saúde, sendo a principal estratégia de comunicação a transmissão de conhecimentos. Assim, a educação limita-se a um foco preventivo, reducionista e pouco ligado com a perspectiva de empoderamento das pessoas, reforçando o entendimento da saúde como a simples ausência de patologia ${ }^{5}$. Com a finalidade de desempenhar eficazmente a prescrição de hábitos e comportamentos saudáveis, nesse modelo educativo, em muitas ocasiões, são usadas estratégias argumentativas e de coerção. No campo das técnicas pedagógicas, há predominância de palestras e grupos, com o uso de cartazes, cartilhas e folhetos. Existe, também, uma supervalorização da comunicação verbal e da unilateralidade com pequenas possibilidades de diálogo. A realidade considerada sempre é a do educador; os educandos, por sua vez, são objetos que recebem informações e prescrições ${ }^{10}$.

Os teóricos criticam o modelo hegemônico por não considerar os determinantes psicossociais e culturais do comportamento, além de tratar o indivíduo como objeto de intervenção, desprovido de um saber sobre saúde. Assim, não se considera que todo comportamento humano é pautado em valores, crenças e representações da saúde e da doença ${ }^{5,11}$. É visto, ainda, como instrumento de dominação e transferência de responsabilidades do cuidado, além de não contribuir com o princípio da integralidade e a prática da promoção da saúde ${ }^{5,7}$.

Dividindo os mesmos espaços institucionais nos serviços de saúde encontra-se o modelo educativo dialógico, pautado na prática libertadora, em uma relação bilateral entre quem educa e quem é educado ${ }^{6}$. Para este modelo, o diálogo é essencial, já que o usuário é reconhecido como sujeito portador de um conhecimento, mas não é necessário que o saber do indivíduo seja condizente com o saber técnico-científico. Assim, o conhecimento prévio do sujeito nunca é deslegitimado, possibilitando que a educação em saúde tenha, como ponto de partida, as condições concretas de vida das pessoas ${ }^{5,7}$. 
Considera-se que a educação dialógica permite a teorização de soluções aos problemas locais, sendo um caminho para a reorientação das práticas em saúde rumo à superação do biologicismo, do autoritarismo e da fragmentação. Possibilita a construção da integralidade na prática e o respeito às condições e representações da população sobre os diversos aspectos do viver ${ }^{5,12}$.

Desse modo, é importante refletir sobre a prática educativa como produtora de cuidado em saúde, e, para tanto, percebeu-se a necessidade de se aproximar das concepções de educação em saúde dos enfermeiros envolvidos no contexto da APS. Assim, é possível revelar a relação existente entre os profissionais, seus instrumentos de trabalho, as concepções educativas e o modo de cuidar cotidianamente das pessoas.

Após essa reflexão, elaborou-se o presente estudo, cujo objetivo foi analisar, a partir da percepção dos enfermeiros, a prática da educação em saúde no contexto da Estratégia Saúde da Família de Montes Claros/Minas Gerais; e, também, desvelar as fundamentações pedagógicas e os seus significados dentro do processo de trabalho da equipe.

\section{Metodologia}

Trata-se de um trabalho qualitativo e descritivo, capaz de demonstrar os significados e intenções da prática educativa em saúde no contexto do processo de trabalho do enfermeiro da $\mathrm{ESF}^{13}$. O cenário de estudo, a cidade de Montes Claros/Minas Gerais, é um centro urbano e polo regional de saúde e educação. O município possui uma rede de saúde composta por equipes da ESF, do Programa de Agentes Comunitários de Saúde (PACS), centros de saúde tradicionais e hospitais gerais. Na ocasião em que os dados foram coletados, a ESF municipal contava com um quantitativo de 59 equipes, entre as localizadas na região urbana e rural, traduzindo uma cobertura populacional de, aproximadamente, 50\%. Destaca-se a existência, no município, do Programa de Residência Multiprofissional em Saúde da Família, promovido pela Universidade Estadual de Montes Claros (Unimontes), que insere profissionais residentes nas equipes municipais de saúde da família.

Escolheu-se, como referencial teórico para o estudo, a dialética, com a finalidade de se debaterem as relações entre consciência e suporte material, tendo como plano de fundo uma perspectiva histórica, pois considera-se que a produção da saúde acontece em um espaço repleto de vivências e significados formados nas relações dos meios cultural e social do território e a proposta de trabalho da equipe de saúde. É dessa relação, por vezes conflituosa, que o percurso histórico dos usuários e profissionais é construído e as práticas em saúde produzidas ${ }^{4,13}$.

Participaram da pesquisa oito enfermeiros de distintas equipes da ESF de Montes Claros/Minas Gerais, profissionais que, dentre suas diversas atribuições, têm como destaque a educação em saúde, fazer histórico do cuidado primário de enfermagem ${ }^{14}$. Para a seleção dos sujeitos da pesquisa, foram utilizados os seguintes critérios de inclusão: atuar em uma equipe da ESF, no mínimo, há um ano; desenvolver alguma forma de atividade educativa coletiva com a comunidade; possuir ou estar cursando Especialização em Saúde da Família na Modalidade de Residência; e aceitar participar do estudo.

A coleta de dados processou-se pela aplicação da entrevista não estruturada, que permite a descrição de um objeto de investigação de modo abrangente, favorecendo o dialogismo ${ }^{13}$. Para a realização da entrevista, propôs-se, aos participantes, a assinatura do Termo de Consentimento Livre e Esclarecido. Os dados foram coletados pela gravação de áudio e tratados segundo a técnica da análise do discurso.

Após transcrição rigorosa, o conteúdo das entrevistas foi lido de forma profunda e exaustiva em busca da discursividade do texto, considerando a conjuntura de produção do discurso registrada em um diário de campo e as condições históricas do cenário estudado. De modo gradativo, as formações discursivas comuns nas falas dos sujeitos foram agrupadas em categorias empíricas iniciais. Depois do aprofundamento da leitura, construiu-se um mapa que facilitou o processo de organização das ideias, de modo que produziu as categorias empíricas definitivas. Os discursos foram identificados por códigos indicativos dos sujeitos-falantes $\left(E_{1}\right.$ a $\left.E_{8}\right)$, preservando, dessa maneira, seu anonimato ${ }^{13,15}$. 
Assim, estabeleceram-se categorias empíricas desveladoras do cotidiano de trabalho relacionado à educação em saúde conduzida pelos enfermeiros, contendo formações ideológicas capazes de retratar a discursividade, em especial, nas relações dinâmicas e históricas ${ }^{13,15}$.

\section{Resultados e discussão}

Após a análise dos dados, houve a emergência de duas categorias empíricas centrais e contraditórias: a primeira, com práticas e ideologias educativas que se aproximam de um fazer dialógico, e, a segunda, composta por fazeres e ideias circunscritas sob um referencial hegemônico.

\section{A Educação em Saúde dialógica}

A institucionalização de um espaço de participação dos sujeitos sociais nos serviços de saúde, uma das premissas do Sistema Único de Saúde (SUS), perpassa a reflexão crítica das práticas de educação desenvolvidas com a população ${ }^{12}$. Neste sentido, para que uma prática educativa possa se aproximar do dialogismo, necessita posicionar a participação do usuário na centralidade do processo ${ }^{6}$, como no discurso a seguir:

"E a equipe, ela tenta estimular ao máximo essa questão. Então, assim a participação dos usuários, ela é fundamental $[\ldots]^{\prime \prime} . \mathrm{E}_{7}$

Em um trabalho qualitativo, cujo cenário foi a ESF de Sobral/Ceará, com o objetivo de analisar a práxis educativa de enfermeiros, alguns profissionais relataram o diálogo com a comunidade como uma forma de escuta de seus problemas reais, possibilitando sua participação ativa. Este fato foi caracterizado como um movimento reflexivo e crítico dos enfermeiros na recondução dos seus fazeres educativos, de forma a valorizar a participação da comunidade ${ }^{16}$, conforme o seguinte relato:

“[...] é trabalhada uma abordagem bem participativa. Dessa forma que a gente desenvolve os grupos aqui". $\mathrm{E}_{5}$

Assumir essa postura é difícil, pois, historicamente, as práticas educativas na atenção à saúde valorizam o saber científico, representado pelas demandas do serviço, em lugar da participação dos usuários ${ }^{7}$. Contraditoriamente, em outro estudo, com o objetivo de conhecer a percepção de enfermeiros da ESF de Uberaba/Minas Gerais sobre a educação em saúde, demonstrou-se a postura desses profissionais em valorizar a participação das pessoas por meio da socialização de experiências e significados da comunidade nas práticas educativas ${ }^{17}$, como, também, se observa nos trechos seguintes:

“[...] não tem nenhum assunto fixo, é a partir da demanda que a gente estará fazendo a orientação, a educação em saúde." $\mathrm{E}_{3}$

"Nesses grupos vão trabalhar temas que surgem da demanda do próprio usuário [...]". $\mathrm{E}_{5}$

O processo educativo dialógico tem como matéria-prima, além da demanda de saber, o conhecimento prévio da população, adquirido no trabalho e na vida ${ }^{7}$. Nesse sentido, o papel do educador é construir um novo saber, tendo como fundamentos as necessidades dos educandos:

"A gente sempre tenta trabalhar a partir do conhecimento que as pessoas já têm, nunca fazendo palestras ou reuniões já pré-determinadas. Elas sempre partem da demanda que a população tem e a partir do conhecimento que eles já têm, a gente tenta construir uma nova conduta, uma nova postura. Diante dos problemas levantados, é realizada uma abordagem com essas pessoas nos grupos de educação em saúde". $\mathrm{E}_{7}$ 
É importante que o cotidiano do meio popular faça parte da compreensão crítica dos educadores, portanto, é necessário diálogo entre conteúdos programáticos e a realidade cotidiana da população ${ }^{4}$. A partir dessa concepção, a ESF emerge como cenário privilegiado para o desenvolvimento da educação em saúde dialógica, pois se insere em determinado território e está ligada permanentemente ao cotidiano das pessoas ${ }^{12}$, permitindo que o educador ouça os anseios dos cidadãos com mais facilidade por meio do diálogo:

“E a gente pergunta no final o que eles sugerem para o tema da próxima reunião e aí a gente já coloca isso anotado, para na próxima reunião a gente abordar aquele tema que foi sugerido e elas já vêm, as mesmas que vieram nas outras, já vêm sabendo qual vai ser o tema a ser tratado". $\mathrm{E}_{2}$

Nesse recorte discursivo, fica evidente que a educação realizada não se restringe apenas aos saberes do educando, mas avança o senso comum, de modo que os temas são diferentes a cada novo encontro. Isso permite uma construção contínua e significativa do saber por meio do diálogo entre conhecimento popular e científico ${ }^{18}$.

Sabe-se que, para realizar uma prática educativa participativa, é preciso trabalhar com alguma estratégia pedagógica que comungue com essa visão ${ }^{6}$. Uma possibilidade metodológica é a educação problematizadora, que vem ganhando espaço no processo de trabalho da ESF por propiciar o envolvimento reflexivo e a autonomia dos indivíduos ${ }^{14}$, como relatado a seguir:

"[...] a gente faz o grupo usando uma metodologia problematizadora, então não tem palestra, não tem imposição de ideias $[\ldots]^{\prime \prime}$. $\mathrm{E}_{6}$

De acordo com um estudo qualitativo realizado com profissionais de equipes de saúde da família do município de Santa Marina/Paraná, com o objetivo de analisar suas concepções sobre educação em saúde, parte dos trabalhadores buscam uma relação educativa mais próxima da reflexão, do diálogo e da problematização ${ }^{19}$. A prática educativa problematizadora parte do princípio de que o educando é voltado epistemologicamente para a curiosidade e para a apropriação dos significados do objeto ${ }^{4}$. Nessas circunstâncias, a educação deve ser aberta, horizontal, libertadora, com o educador disponível para ouvir e não só para falar:

"Tanto o médico quanto o enfermeiro, a gente conversa com esses pacientes, abre um espaço para o diálogo, pergunta o que eles querem discutir, quais são os assuntos, do que realmente eles querem estar debatendo naquele dia. E a gente dá essa liberdade, toda vez que eles escolhem um tema a gente trabalha aquele tema com eles, de forma que eles vão falar". $\mathrm{E}_{6}$

O espaço criado por essa metodologia permite a obtenção de uma educação dialética, em que não há saber verdadeiro, tudo é relativo, negado, complementado ou superado por outros saberes ${ }^{4}$. Estudo realizado também no município de Montes Claros/Minas Gerais, com usuários da saúde da família, com o objetivo de compreender sua perspectiva sobre a educação em saúde e seu significado no cotidiano, identificou a existência de práticas educativas problematizadoras, mesmo que ainda disputando espaço no cotidiano do processo de trabalho das equipes ${ }^{20}$.

A educação problematizadora permite que o profissional entenda melhor o comportamento dos usuários e as situações de saúde e doença que os influenciam ${ }^{7}$. Assim, é possível desenvolver uma abordagem que supere a tradicionalidade prescritiva da área da saúde:

“Então eles são pacientes pontuais que a gente tem tentado trabalhar não de uma maneira prescritiva pra eles, que eles têm que tomar remédio, que eles têm que fazer dieta, que eles têm que fazer caminhada, mas levando a refletir sobre isso! Sobre essas questões, senão é difícil! Porque a motivação, ela tem que ser do próprio paciente, eu não posso fazer ele aderir às solicitações, ele que tem que refletir e pensar sobre a atitude dele". $\mathrm{E}_{6}$ 
Evidencia-se, no relato, uma percepção mais ampla do processo de estímulo ao autocuidado por meio da educação problematizadora, sendo notável a preocupação de afastar a educação da prática prescritiva, mas, contrariamente, trabalhar em uma perspectiva mais aberta, estimuladora e reflexiva. Portanto, o estímulo para o aprendizado deve ser do educando, intrínseco, pautado na reflexão de sua problemática, a fim de possibilitar uma tomada de decisão segura ${ }^{4}$.

Desse modo, no contexto da saúde, a constituição de sujeitos autônomos passa pela reconstrução de significados e atitudes, mas, necessariamente, depende também do desenvolvimento do autocuidado, principal objetivo educativo no contexto da APS ${ }^{17,19}$. A filosofia do autocuidado pressupõe que o sujeito seja o mais independente possível no atendimento às suas necessidades de saúde e responsável pelo cuidado de si, sempre apoiado por profissionais e familiares ${ }^{2}$. No próximo relato, percebe-se essa preocupação do educador:

“A primeira coisa é a questão da responsabilização das pessoas pela própria saúde. A gente tenta passar pra eles o seguinte: não é o médico, não é o enfermeiro, não é a equipe de saúde que é responsável pela sua saúde é você mesmo, a gente está aqui para colaborar naquilo que for cabível à gente, a nós". $\mathrm{E}_{7}$

O discurso centra-se na responsabilização do indivíduo por sua saúde, e, apesar do jogo de poder evidente nas entrelinhas, observa-se a disponibilidade da equipe de saúde em colaborar com o usuário. Em estudo já citado ${ }^{19}$, os profissionais da equipe de saúde da família identificaram, na prática educativa, uma tecnologia de trabalho que possibilita a promoção do autocuidado, ao auxiliar na sensibilização e compreensão das pessoas acerca das demandas e necessidades de cuidados em saúde.

Nos discursos dos enfermeiros, além do modelo problematizador, evidencia-se a utilização do lúdico como estratégia de facilitação da participação do usuário nos grupos educativos:

“[...] elabora alguma dinâmica relacionada ao tema e conduz o grupo de forma bem participativa...". $E_{2}$

Dinâmicas e brincadeiras são ferramentas intrínsecas do processo educativo, podendo potencializar a participação e o aprendizado das pessoas ${ }^{12}$. No contexto da atuação do profissional de enfermagem, a educação em saúde é a área que mais permite o uso da criatividade e do lúdico como ferramentas de trabalho ${ }^{21}$, como se observa a seguir:

\section{"[...] a gente faz em forma de brincadeiras [...]". $\mathrm{E}_{8}$}

O desenvolvimento da capacidade de aprendizagem do ser humano está estreitamente entrelaçado com o mundo da afetividade, ou seja, da paixão e da curiosidade. Consequentemente, estabelecer dinâmicas ou processos educativos que trabalhem com estas dimensões da essência humana produz resultados mais satisfatórios e transformadores ${ }^{22}$, como no relato a seguir:

“Então é interessante, é muito interessante isso que a gente está fazendo, [...] a gente faz uma coisa bem descontraída e muitas vezes eu faço ginástica com eles e técnica de relaxamento, faço brincadeiras e isso traz uma sensação de descontração muito grande e são essas as técnicas que eu utilizo! De relaxamento, ginástica, brincadeirinhas. Isso faz com que as pessoas se sintam mais envolvidas no grupo, então ela tem mais liberdade pra falar porque ela viu que o clima é um clima assim harmonioso, de descontração $[\ldots]^{\prime \prime} . \mathrm{E}_{6}$

Abordagens lúdicas facilitam a permuta de conhecimento, possibilitando, aos sujeitos, dividirem suas experiências pessoais que se cruzam e permitem uma reflexão comum. Entretanto, é preciso saber que as atividades lúdicas não devem se limitar ao simples objetivo de descontrair ou alegrar o processo educativo, pois, quando utilizadas de forma restrita, revelam um processo educativo ingênuo ao reproduzir um modelo pedagógico alienador em uma roupagem dialógica7,12. Assim, é preciso que 
o educador garanta que o conteúdo da dinâmica ou atividade lúdica esteja coerente com a proposta e objetivos educativos:

"[...] a gente conduz a reunião de idosos de forma bem lúdica, assim, de forma que, seja um teatro, uma dança, uma brincadeira que aí, é o que eles gostam mais, mas enfocando algum assunto [...]". $\mathrm{E}_{2}$

Segundo uma investigação qualitativa, realizada também no município de Montes Claros/Minas Gerais, com o objetivo de analisar, a partir da percepção do usuário da ESF, a prática da educação em saúde, o uso de atividades lúdicas de forma contextualizada aos objetivos pedagógicos é uma estratégia eficaz para promover a reflexão e satisfação do usuário durante a educação em saúde ${ }^{23}$.

\section{A Educação em Saúde hegemônica}

A ideologia educativa hegemônica, em suas variadas vertentes, também está presente nos discursos dos sujeitos deste estudo. Nota-se, primeiramente, que ainda persiste uma percepção de comunicação, entre enfermeiro e cidadão, centrada no caráter informativo, com atitude paternalista e voltada para a mudança de hábitos e adoção de comportamentos saudáveis ${ }^{5}$, como é possível perceber a seguir:

\footnotetext{
"Então a gente, nos grupos, tem que mostrar para o paciente a sua condição de saúde! Falar assim: você está assim, assim está a sua saúde, o que que você tem que fazer para melhorar, o que que você pode. Você tem que fazer isso, isso e isso!". $\mathrm{E}_{4}$
}

A proposta pedagógica apresentada fundamenta-se no entendimento de que o indivíduo, quando recebe a informação, é capaz de decidir a prevenir doenças e agravos, assim como mudar hábitos e condutas $^{5}$. Em um estudo anteriormente referido, foram encontrados resultados semelhantes, visto que o discurso dos profissionais enfermeiros estava permeado pela ideologia educativa de mudança comportamental ${ }^{11}$.

Convém ressaltar que a educação para a mudança de comportamento é necessária e interessante, o problema reside no fato de o educador concentrar-se nessa abordagem de modo a não abrir espaço para o diálogo, não ouvindo as dificuldades das pessoas em gerenciar sua própria vida, muitas das quais estão relacionadas ao contexto social. Assim, o educador não é capaz de descobrir situações que influenciam diretamente o itinerário terapêutico percorrido pelas pessoas com adoecimento crônico ${ }^{12}$.

Investigações qualitativas já citadas e realizadas com enfermeiros de outras localidades apresentam discursos carregados pela prática prescritiva e normativa. As atitudes educativas são excessivamente intervencionistas e de olhar reducionista e fiscalizador, com a finalidade de garantir estilos de vida saudáveis ${ }^{16,17}$. Este mesmo discurso apresenta ecos na realidade estudada:

“Traçar metas, traçar, né! Com um tempo para que o usuário cumpra essa meta e depois pedir para que ele volte, reavaliar e mostrar: olha você está assim, você conseguiu, você melhorou, você não melhorou, você piorou! Isso para que o paciente saiba da sua condição de saúde, que ele se sinta estimulado". $\mathrm{E}_{4}$

Nessa abordagem, avaliam-se os comportamentos que, segundo a lógica científica, são adequados ou não para a vida das pessoas. A solução é apresentada pelo educador na forma de normas traduzidas na utilização de medicamentos, cumprimento de prescrições e mudança de hábitos ${ }^{12}$. No mesmo ambiente de pesquisa, na visão dos usuários, esse estilo de educar é frequente, conforme estudos qualitativos mencionados anteriormente ${ }^{20,23}$.

Nesse modo de educar, a subjetividade e o contexto social dos indivíduos são desconsiderados, e o processo de cuidado envolve o silenciar e não fazer perguntas, o que produz passividade, como se as pessoas fossem corpos vazios, receptáculos de informações e prescrições ${ }^{24}$. Nesta mesma direção, estão as práticas educativas orientadas exclusivamente para a dimensão biológica do adoecimento, que 
consideram como causa dos problemas de saúde os chamados comportamentos ou fatores individuais de risco, como: vida sedentária, consumo de gorduras, açúcares e fumo ${ }^{12}$ :

“É, nos grupos de educação em saúde (pausa) serão desenvolvidas estratégias, pra quê? Pra identificar em cada usuário os fatores de risco!". $E_{4}$

Nota-se que a preocupação excessiva com o contexto biológico traduz um olhar fragmentado e reducionista dos indivíduos, em descompasso com o princípio da integralidade do cuidado que se caracteriza por ir além da doença e do sofrimento manifestado, em busca da apreensão das mais abrangentes necessidades do sujeito. Esse modo de conduzir o processo educativo é reflexo da atuação de profissionais em um contexto de práticas curativas, contradizendo a proposição da ESF em reorientar o modelo assistencial ${ }^{25}$ :

"[...] os grupos de hipertensos e diabéticos, eles ocorrem de acordo com a classificação de risco do Plano Diretor, então primeiramente nós fizemos a estratificação de risco de todos os pacientes hipertensos e diabéticos. A partir dessa estratificação, nós agrupamos as pessoas de acordo com o risco, e aí a periodicidade da realização desses grupos a gente segue conforme o preconizado pelo Plano Diretor [...]". $\mathrm{E}_{6}$

Quando no serviço de saúde opera, mesmo que de forma velada, o modo curativista de cuidar, vários problemas são postos ao processo de trabalho dos profissionais da ESF, dificultando que eles utilizem o princípio da integralidade como uma ferramenta fundamental do cuidado ${ }^{17}$. Uma situação ilustrativa é a própria organização das atividades educativas coletivas em função da doença, como no discurso a seguir: "Com relação ao outro grupo de patologia [...]" $E_{1}$

Em um estudo já discutido, foi constatada a focalização da educação em saúde na abordagem de doenças ou agravos como uma extensão do atendimento individual em consultório ${ }^{19}$. Outro estudo apresentou resultados semelhantes, pois as temáticas desenvolvidas relacionavam-se com doenças prevalentes. Desse modo, infere-se que existem práticas educativas que ainda estão orientadas somente para doenças específicas, centrando suas ações na diminuição de suas complicações ${ }^{16}$.

Há que se considerar, para explicar este contexto, o processo de formação profissional para o trabalho com a saúde da família. Vários cursos de graduação ou formação continuada ainda possuem raízes no famoso modelo flexneriano de ensino, que é incoerente com os desafios propostos pela educação em saúde no contexto da ESF². Essa reflexão se faz presente no trecho discursivo seguinte:

"[...] mas a gente ainda não consegue desvincular ainda da patologia não, infelizmente a gente faz grupos de acordo com a patologia [...]". $\mathrm{E}_{6}$

A organização das atividades educativas coletivas a partir da doença pode contribuir para uma compreensão descontextualizada, pelos cidadãos, das diferenças entre a saúde e o adoecimento e do propósito de promoção da saúde e autocuidado ${ }^{20}$. Por outro lado, é um equívoco tentar explicar esta circunstância como uma consequência direta da prática ou experiência dos enfermeiros, pois existe certa contradição, dentro das próprias orientações institucionais, ao estabelecer, nos manuais que orientam o processo de trabalho, a criação desses grupos que são organizados por patologias:

“Então, hipertensos, diabéticos, aí como é que a gente aborda? Normalmente a gente segue as Linhas Guias do Plano Diretor porque ele já sugere a maneira como conduzir com as patologias". $\mathrm{E}_{1}$

Conforme asseguram algumas autoras ${ }^{11}$, existe uma mudança importante no discurso oficial da educação em saúde nos documentos oficiais do setor saúde. Trata-se de uma alteração do trabalho tradicional para uma abordagem direcionada à perspectiva participativa. Entretanto, ainda são 
encontradas orientações que denotam uma interpretação nítida em reforçar padrões de saúde que são concebidos para o povo pelo governo.

Em estudo qualitativo já citado, encontrou-se, nos discursos e observação, uma prática de enfermeiros baseada em generalidades, fundamentada por programas predefinidos pelo Ministério da Saúde. Desse modo, a função das diretrizes ultrapassa o papel de nortear as atividades e passa a substituir as necessidades do território ${ }^{16}$.

Ainda no campo das fundamentações pedagógicas, tem-se o chamado comportamentalismo, que entende a aprendizagem/educação como condicionamento do ser humano, ou seja, é necessário que exista um estímulo para que se obtenha um resultado. Assim, de acordo com essa forma de pensar a educação, o motor da aprendizagem é externo, já que o aprendiz necessita receber estímulos para aprender ou instituir um processo de mudança ${ }^{12}$. Observa-se, nas entrelinhas do seguinte discurso, uma aproximação com essa ideologia:

"Sempre que possível a gente, não como atrativo, mas como uma forma de gratidão mesmo
pela presença deles, a gente oferece um lanche! Agora em relação ao resultado disso, a gente
percebe que, sempre que tem um a mais, alguma coisa a mais além da discussão, além dos
comentários, a reunião ela é mais produtiva e as pessoas saem mais satisfeitas e assim mais
motivadas com aquilo que elas aprenderam ou que elas assimilaram daquele encontro ali". $E_{7}$

Nessa pedagogia, nota-se que o educador condiciona o educando para que ele emita respostas desejadas, por meio do uso de estímulos e recompensas, ou seja, o "lanche". Esse método de trabalho enfatiza os resultados comportamentais e, geralmente, forma um sujeito que não problematiza, pois reproduz respostas consideradas adequadas e preestabelecidas ${ }^{8}$ :

“E no grupo de gestantes, a gente percebe dificuldades! Uma das dificuldades, é que a gente gostaria de ter alguma coisa para estimular mais a participação, como um brinde pra sortear! Porque a gente percebe que é uma coisa importante nesses grupos que a gente tem determinada dificuldade [...] que elas se sentem mais valorizadas, elas se sentem é (pausa) mais estimuladas mesmo a estarem vindo". $E_{7}$

Nota-se que a visão educativa está centrada nas sensações como reflexo da realidade e, nesse modo de ver a educação, não existe saber prévio, desejos ou interesses de aprendizagem oriundos do educando ${ }^{12}$. O modo de educar condicionador, fundamentado em uma política de barganha, é reforçado a seguir:

“O grupo de gestante que aqui na unidade a gente não tá realizando! Nós até começamos ano passado, mas a adesão das gestantes estava muito pequena e a agente atribuiu ao fato de não ter algo mais sólido e motivador para que a gestante viesse, que os grupos de gestantes aqui eram mesmo de orientação! A gente não tinha muito, como é que se diz, não tinha uma moeda de troca para gestante, sabe? Então, a gente marcava vinham duas, vinham três". $E_{4}$

Esse modelo baseado em uma "moeda de troca" utiliza não somente recompensas concretas, mas, também, as simbólicas, situadas no campo dos significados:

"O enfermeiro! Eu, no caso, os grupos que eu faço, eu faço junto com o médico, que a presença do médico aqui ela é um grande (pausa), como é que se diz, um elemento importante pra fazer com que o paciente ele esteja presente nos grupos [...] Então, é hoje a estratégia que está sendo usada pra fazer com que o paciente participe dos grupos é a presença do médico!". $\mathrm{E}_{4}$

É notável que a sociedade moderna confere ao profissional médico um "poder terapêutico", que legitima um modelo de cuidado à saúde medicalizado e fundamentado na cura. O cidadão, tendo 
como referência sua experiência de saúde e doença, cria e recria símbolos e significados da patologia e de como evitá-la, influenciando amplamente suas condutas e concepções em relação aos profissionais e às práticas de educação em saúde ${ }^{11}$. A solução para melhorar a saúde, de acordo com o senso comum, se restringe ao acesso ao profissional médico, fato que confronta diretamente a proposta de multiprofissionalidade apresentada pela ESF².

No transcorrer do discurso, o sujeito justifica sua colocação:

“Porque com a presença do médico, o paciente vê uma possibilidade de troca, sabe? É, por exemplo, ele pode trocar uma receita, ele pode falar sobre uma outra queixa que ele tem. Então, assim, a experiência que a gente tem é que os grupos só com enfermeiro eles não têm muita adesão aqui!". $E_{4}$

Na prática cotidiana da ESF, ainda é comum condicionar a troca de uma receita de medicamentos ou a realização de consultas rápidas do tipo queixa e conduta à participação de reuniões educativas. Nessa educação condicionadora, geralmente, os profissionais ensinam como as pessoas devem se comportar em relação a seus hábitos de vida ${ }^{6}$. A promoção da saúde perde espaço e o cuidado situa-se em descompasso com a integralidade do ser humano ${ }^{5,7}$. A educação torna-se um instrumento de controle, uma obrigação que deve ser cumprida para que a pessoa receba, como recompensa, outras modalidades de cuidado9:

\footnotetext{
"No entanto, no grupo de hipertensos e diabéticos tem um ganho secundário, porque eles deverão vir de qualquer maneira ou pelo menos a gente pressupõe que eles tenham que vir, por quê? É o momento de renovar a receita e de solicitar ou ver exames, por causa do acompanhamento de hipertensos e diabéticos, mesmo porque eu não tenho muita alternativa $[\ldots]^{\prime \prime} . \mathrm{E}_{1}$
}

Um estudo qualitativo com membros de uma equipe da ESF de Cachoeira do Campo/Minas Gerais, cujo objetivo foi conhecer suas perspectivas sobre a educação em saúde, apresenta uma realidade muito próxima ao que os discursos desvelam, com a utilização da pedagogia do condicionamento como estratégia para melhorar a adesão aos grupos educativos ${ }^{14}$. Outros estudos, já referidos, segundo a perspectiva de usuários, indicam que as práticas pedagógicas condicionadoras são corriqueiras no cuidado das equipes de ESF de Montes Claros ${ }^{20,23}$.

Ressalta-se que essa modalidade de educação pode levar a população ao conformismo, em que o educando compreende que sua participação está vinculada a uma recompensa e pode ficar limitado a essa visão. A originalidade e a criatividade dos educandos são suprimidas, ocasionando a manutenção da dependência e do estado de inércia da população que não é estimulada a refletir sobre sua realidade ${ }^{8}$.

\section{Considerações finais}

Este estudo revelou, a partir da análise do discurso de enfermeiros vinculados à saúde da família, que, no campo das ideologias pedagógicas, as práticas educativas desenvolvidas podem ser dicotomizadas em duas categorias: dialógicas e hegemônicas.

Na primeira, estão situadas as práticas pedagógicas que estimulam a participação do educando e que iniciam o percurso educativo a partir do conhecimento prévio das pessoas; e, também, os modos de proporcionar problematização e diálogo nos momentos educativos, conduzindo usuários e profissionais a um processo de autocuidado apoiado. Para tanto, utilizam-se dinâmicas e brincadeiras que mobilizam, sempre com uma finalidade pedagógica, os sentimentos e vivências do educando.

No campo oposto, reduto de práticas hegemônicas, encontra-se uma educação autoritária, prescritiva, restrita à mudança de comportamentos e, além disso, baseada fortemente em aspectos biológicos do processo de saúde e doença, como os fatores de risco. Muitas vezes, possuem como 
eixo norteador a patologia, reduzindo a condição humana a um diagnóstico médico que deve ser controlado a todo custo. Para alcançar os resultados, o modelo trabalha com o condicionamento das pessoas por meio de recompensas, como receitas, brindes e lanches.

Interessante saber que, na concretude da realidade, as práticas contraditórias se misturam, pois, suas ideologias ecoam nos discursos dos mesmos sujeitos, o que leva à interpretação de que o campo de práticas da educação em saúde, no contexto estudado, encontra-se em um movimento de devir.

\section{Colaboradores}

Edmar Rocha Almeida e Cinara Botelho Moutinho responsabilizaram-se pela elaboração do projeto de pesquisa, coleta e análise dos dados e produção do manuscrito. Maisa Tavares de Souza Leite responsabilizou-se pela orientação da elaboração do projeto, coleta e análise dos dados, assim como pela revisão do manuscrito.

\section{Referências}

1. Starfield B. Atenção primária: equilíbrio entre necessidades de saúde, serviços e tecnologia. Brasília (DF): Unesco, Ministério da Saúde; 2002.

2. Mendes EV. O cuidado das condições crônicas na atenção primária à saúde: o imperativo da consolidação da estratégia da saúde da família. Brasília (DF): Organização Pan-Americana da Saúde; 2012.

3. Freire P. Pedagogia do oprimido. 11a ed. São Paulo: Paz e Terra; 1994.

4. Freire P. Política e educação. 8a ed. Indaiatuba: Villa das Letras; 2007.

5. Alves VS. Um modelo de educação em saúde para o Programa Saúde da Família: pela integralidade da atenção e reorientação do modelo assistencial. Interface (Botucatu) [Internet]. 2005; 9(16):39-52 [acesso 2013 Jan 20]. Disponível em: http://www.scielo.br/ pdf/icse/v9n16/v9n16a04.pdf. DOI: 10.1590/S1414-32832005000100004.

6. Vasconcelos $M$, Grilo $M J C$, Soares $S M$. Práticas pedagógicas em atenção primária à saúde: tecnologias para abordagem ao indivíduo, família e comunidade. Belo Horizonte: Nescon/UFMG, Coopmed; 2009.

7. Vasconcelos EM. Educação popular e a atenção à saúde da família. 4a ed. São Paulo: Hucitec; 2008.

8. Bordenave JDE, Pereira AM. Estratégias de ensino-aprendizagem. 30a ed. Petrópolis: Vozes; 2010.

9. Freire P. Educação e mudança. 30a ed. São Paulo: Paz e Terra; 2007.

10. Figueiredo MFS, Rodrigues-Neto JF, Leite MTS. Modelos aplicados às atividades de educação em saúde. Rev Bras Enferm [Internet]. 2010; 63(1):117-21 [acesso 2014 Out 3]. Disponível em: http://www.scielo.br/pdf/reben/v63n1/v63n1a19.pdf. DOI: 10.1590/ S0034-71672010000100019. 
11. Gazzinelli MF, Gazzinelli A, Reis DC, Penna CMM. Educação em saúde: conceitos, representações sociais e experiências de doença. Cad Saude Publica. 2005; 21(1):200-6.

12. Ministério da Saúde. Secretaria de Gestão Estratégica e Participativa. Departamento de Apoio à Gestão Participativa. Caderno de educação popular e saúde. Brasília (DF): MS; 2007.

13. Minayo MCS. O desafio do conhecimento: pesquisa qualitativa em saúde. 11a ed. São Paulo: Hucitec; 2010.

14. Fernandes MCP, Backes VMS. Educação em saúde: perspectivas de uma equipe da Estratégia Saúde da Família sob a óptica de Paulo Freire. Rev Bras Enferm [Internet]. 2011; 63(4):567-73 [acesso 2014 Out 3]. Disponível em: http://www.scielo.br/pdf/reben/ v63n4/11.pdf. DOI: 10.1590/S0034-71672010000400011.

15. Orlandi EP. Análise do discurso: princípios \& procedimentos. 3a ed. Campinas: Pontes; 2001.

16. Silva $C P$, Dias $M S A$, Rodrigues $A B$. Práxis educativa em saúde dos enfermeiros da Estratégia Saúde da Família. Cienc Saude Colet. 2009; 14 Supl 1:1453-62.

17. Cervera DPP, Parreira BDM, Goulart BF. Educação em saúde: percepção dos enfermeiros da atenção básica em Uberaba (MG). Cienc Saude Colet. 2011; 16 Supl $1: 1547-54$

18. Freire P. Pedagogia da esperança: um reencontro com a pedagogia do oprimido. $14 a$ ed. São Paulo: Paz e Terra; 2007.

19. Pinafo E, Nunes EFPA, González AD, Garanhani ML. Relações entre concepções e práticas de educação em saúde na visão de uma equipe de saúde da família. Trab Educ Saude. 2011; 9(2):201-21.

20. Figueiredo MFS, Rodrigues-Neto JF, Leite MTS. Educação em saúde no contexto da Saúde da Família na perspectiva do usuário. Interface (Botucatu) [Internet]. 2012; 16(41):315-29 [acesso 2014 Out 10]. Disponível em: http://www.scielo.br/pdf/icse/ v16n41/a03v16n41.pdf. DOI: 10.1590/S1414-32832012000200003.

21. Trezza MCSF, Santos RM, Santos JM. Trabalhando educação popular em saúde com a arte construída no cotidiano da enfermagem: um relato de experiência. Texto Contexto Enferm. 2007; 16(2):326-34.

22. Morin E. Os sete saberes necessários à educação do futuro. 2a ed. Brasília (DF): Unesco; 2000.

23. Almeida ER, Moutinho CB, Leite MTS. A prática da educação em saúde na percepção dos usuários hipertensos e diabéticos. Saude Debate [Internet]. 2014; 38(101):328-37 [acesso 2014 Nov 2]. Disponível em: http://www.scielo.br/pdf/sdeb/v38n101/01031104-sdeb-38-101-0328.pdf. DOI: 10.5935/0103-1104.20140030.

24. Meyer DE, Félix J, Vasconcelos, MFF. Por uma educação que se movimente como maré e inunde os cotidianos de serviços de saúde. Interface (Botucatu) [Internet]. 2013; 17(47):859-71 [acesso 2014 Set 10]. Disponível em: http://www.scielo.br/pdf/ icse/2013nahead/aop4513.pdf. DOI: 10.1590/S1414-32832013005000033.

25. Alves GG, Aerts D. As práticas educativas em saúde e a Estratégia Saúde da Família. Cienc Saude Colet. 2011; 16(1):319-25. 
Almeida ER, Moutinho CB, Leite MTS.Práctica pedagógica de enfermeros de Salud de la Família en el desarrollo de la Educación en Salud. Interface (Botucatu). 2016; 20(57):389-401.

Este estudio intentó analizar la percepción de los enfermeros y la prática de la educación en salud en el contexto de la Estrategia Salud de la Familia de Montes Claros, Minas Gerais. Se trata de una investigación cualitativa, descriptiva y dialéctica con ocho enfermeros residentes en salud de la familia. Las entrevistas fueron no estructuradas, grabadas y transcriptas para realizar con ellas análisis del discurso. Se revelaron dos categorías empíricas dicotómicas: la educación en salud hegemónica y la práctica dialógica. Las contradicciones del discurso eran evidentes: mientras los sujetos describen una educación participativa y problematizadora, coexisten prácticas basadas en la imposición de ideas así como en el condicionamiento de la población. De este modo, quedó demostrada una realidad plural con avances y retrocesos.

Palabras clave: Educación en salud. Salud de la familia. Atención Primaria para la Salud. Enfermería en Salud Comunitaria. Investigación cualitativa. 
